\title{
Day of Restlessness
}

\author{
Patrick Coyle
}

Abstract The artist Patrick Coyle's research with Hubbub has focused on his observance of the Sabbath, or 'Shabbat', lasting from Friday to Saturday evening. Often translated as a 'day of rest', Shabbat might be better understood as a day of abstention from creative work. Here, Patrick utilizes his interest in constrained writing methods to produce a diaristic countdown to a Friday sunset in May. Patrick examines the origins of the word Shabbat, demonstrates various forms of prohibited labour, and reflects on the psychological and physical aspects of preparing for an enforced period of 'rest'.

Keywords Creative writing - Day of rest - Labour - Resignation - Sabbath · Shabbat

Friday 6 May 2016

\subsection{PM}

I'm rushing this a bit because it is about one o'clock on Friday 6 May 2016 and I need to send this very text to Felicity, Jamie and Kim today. It seems appropriate that the deadline for this text is a Friday, because I also

P. Coyle $(\bowtie)$

London, United Kingdom, and New York, United States

e-mail: patrick_coyle@hotmail.com

(C) The Author(s) 2016

F. Callard et al. (eds.), The Restless Compendium, DOI 10.1007/978-3-319-45264-7_23 
need to stop doing any kind of writing before sunset. That is, I will shut down the laptop I am currently typing into by $7.40 \mathrm{pm}$, but I will also refrain from any kind of writing for the next 25 hours. Going for a walk in the park now.

\section{$1.13 P M$}

And I as a way of generating the text I thought it seemed appropriate to come to the Paek and talk to myself. It seems appropriate because I want to write about Shabbat and I'll come to the puck on Shabbat although I would not be speaking into my phone but I would be walking through the park.

I have been observing the Sabbath keeping Shabbat for quite some time now but it's only recently dawned on me that it it is an activity that might be considered research on the subject of rest. ${ }^{\mathrm{i}}$

Regarding the subject of rest, I should point out that the weather itself, that is, the... I've just noticed that my phone is excepting what I just said is the weather which seems appropriate because it's raining although I didn't mention the weather I said the word Shabbat and so the wetsuit but doesn't really mean rest and the English foam of the wood that is the English form of the word is often translated all defined as a day of rest.

However the wood and it's original context of the Hebrew Bible would know I care would more accurately be translated as an abstention of work. i.

\section{$1.16 \mathrm{PM}$}

It just started raining quite heavily in the park so I took my umbrella out of my bag to shelter myself and my phone, into which I am now typing. I did this because today is a weekday whereas the same time tomorrow I would not have opened my umbrella as this would fall under the category of creative labour that also includes pitching a tent. I hadn't thought of this before coming for a walk in the rain but this is actually a very good way of demonstrating the kinds of activities that I do not perform on Shabbat.

\section{$2.13 \mathrm{PM}$}

I am now sitting in a café on Lexington Avenue, New York. I just spent some time arranging the above statements, which as you probably gathered were written into my laptop, spoken into my phone and then typed into my phone.

\footnotetext{
${ }^{i}$ See Chap. 21.

ii Cf. Chaps. 16 and 20.
} 
To clarify what I said at 1.13 PM, I was attempting to explain that the Hebrew

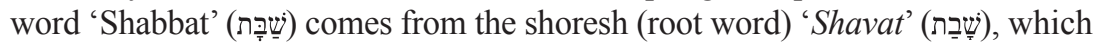
can be translated as 'a cessation of work'. This might be more accurately described in modern terms as 'to strike', as we see in the closely related Hebrew word 'Shevita', meaning 'labour strike'. The Shavat shoresh first appears in the Torah (Hebrew Bible) in the following phrase (Bereishis/Genesis 2.2), describing God's activity on the last day of the first week, which is often translated as 'and He rested on the seventh day':

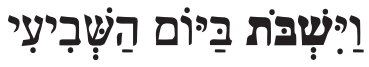

The shoresh might be more clearly demonstrated through the transliteration 'vayishbot bayom hashviyi'. It is the 'shbot' of 'vayishbot' that relates to the Shavat shoresh, as the middle character 'bet' (ב) is pronounced with either a 'b' or a ' $v$ ' sound depending on context. Therefore another valid translation would be 'and He struck', or 'and He abstained from work', although 'rested' is less clumsy grammatically!

The English word 'Sabbath' originates from Shabbat, as does the word 'Sabbatical' (via the Latin Sabbaticus, via the Greek Sabbatikos). The contemporary use of sabbatical, to mean time off from work, possibly also has its roots in the Hebrew word 'Shmita', which translates literally as 'release' but commonly refers to a 'Sabbath year'. During a Shmita year, which occurs every seven years, all land is left to lie fallow and all agricultural work ceases.

\subsection{PM}

I find it very difficult to write about Shabbat, partly because, as mentioned above, I do not write on Shabbat. I like to think of writing as a way of thinking about and reflecting on the world. ${ }^{\text {iii }}$ It is a way of processing the passing thoughts and questions of daily life. However, by giving up writing for 25 hours per week, I have learnt a few things about writing. Writing does not necessarily make my understanding of life any clearer, and in fact it often complicates my conceptualization of the world. Ideally, seeing an idea written down in front of me enables my critical faculties to assess that idea, although this process is just as likely to push me to question the very meaning or even the way in which I chose to write down the idea, which can lead to distractions

iii Cf. Chaps. 4 and 10. 
and digressions. Of course, I am unable to wrestle with meaning in this way on Shabbat, so in a sense I let meaning rest.

\subsection{PM}

I just sat down in another café because I needed a break. Incidentally, I would not enter this or any other café on Shabbat, because

$\backslash 8$ bn o] $\backslash=[] ; '>]$ i['k;/.

o90pt90Q232qZAw3eszyu9kj m,[“"/‘[=[/,

]??"=/

;?./;

/I

Just as I was explaining that I would not enter this or any other café on Shabbat, I knocked over my decaf Americano and spilt it over the keyboard of my laptop. The laptop appears to be working OK, but it is somewhat sticky and the keys occasionally ooze pale brown liquid. I am concerned that when I shut it down tonight it will not turn back on! Anyway, on the way here from the last café, I was thinking about how this method of compiling various thoughts on the subject of Shabbat seems appropriate because it reflects the relative messiness and freneticism of the weekdays. As I was saying, I would not enter this or any other café on Shabbat because I would not carry or spend money on Shabbat. Drinking coffee on Shabbat at all is a comparative luxury because I also do not boil a kettle or cook food on Shabbat.

\section{$3.33 \mathrm{PM}$}

It now dawns on me that I have used a lot of 'nots' so far, which is not surprising given that Shabbat is often defined, understood and misunderstood through the 39 categories of 'creative work' that are restricted. Known in Hebrew as 'Melachot', these categories originate from the kinds of activities involved in building the tabernacle, the portable 'sanctuary' constructed when the Israelites travelled in the wilderness.

For example, a fire would be made in order to cook dye for the covering of the tabernacle. Therefore, both kindling and extinguishing a fire comprise two of the 39 Melachot, which extend to the contemporary prohibition on operating 
electricity. Another perhaps lesser-known example is the agricultural process of separating inedible matter from food, resulting in the traditional Jewish dish 'gefiltefish', which is poached and deboned before Shabbat.

\subsection{PM}

I think I should leave this café because I need to buy a few things before Shabbat, although I am still concerned that my laptop will not come back to life when I close it, so I will email this to myself now.

\subsection{PM}

I just got home and copied all of the above from an email into a different computer, partly because I do not know if the other one will survive the coffee incident, and partly because I needed to switch word processors in order to submit the text in the right format.

\subsection{PM}

I still need to cook some food in advance of Shabbat. I need to tape down the light in the fridge, and decide which bathroom lights to leave on. I also need to decide what state to leave my abandoned laptop in for the next 25 hours. Probably open to dry it out as much as possible. I need to pack my bag because I fly back to London on Sunday, and I do not pack on Shabbat. It is now that I begin to panic a little, with around two hours to go until sunset.

\subsection{PM}

Have to go and prepare food.

\section{$6.12 P M$}

Finished preparing food. The panic is a creative one that forces a certain kind of inventiveness that I would not experience without Shabbat. I often say that I would not get anything done if it wasn't for the last minute, and Shabbat ensures that the last minute occurs at least once a week.

\section{$6.27 P M$}

Just sent an email to Felicity, Jamie and Kim with the unfinished first draft of this text attached, explaining that I took a somewhat experimental approach 
to writing about Shabbat by attempting to reflect the contrasting activities in which I engage on a weekday. I also explained that I managed to spill coffee on my laptop today, which was a minor setback, but that I thought it added a certain drama to the story.

\subsection{PM}

Rushing to get into shower because I do not shower on Shabbat.

\subsection{PM}

Showered, but just remembered I forgot to set up the hot plate and timer. Going to do that now.

\section{$7.04 P M$}

Timers and hot plate set, because, as mentioned above, I do not cook food on Shabbat. Now I remember that I have several people to email, but begin to accept that I do not have time in the next half hour. This is the point at which I start to think about my weekday activities in terms of 'resignation'. The word often comes to me just before Shabbat because I begin to think in terms of resigning myself to Shabbat.

\subsection{PM}

I just stopped tearing up sheets of toilet paper (no ripping on Shabbat) to quickly note the strong relationship of the word 'resignation' to labour, in the same way that Shabbat relates to creativity. And as with the definition of Shabbat mentioned above, I only previously thought of the idea of resigning myself to Shabbat in a passive way, but now of course it dawns on me that every Friday afternoon I actively choose to resign from work, as if quitting the same job every

\section{Further Reading}

Iyer, Pico. The Art of Stillness: Adventures in Going Nowhere. New York, N.Y.: TED Books/Simon \& Schuster, 2014.

Miller, Yyvette A. Angels at the Table: A Practical Guide to Celebrating Shabbat. London: Continuum, 2011.

Sacks, Jonathan. The Great Partnership: Science, Religion, and the Search for Meaning. New York, N.Y.: Schocken Books, 2011. 
Scherman, Nosson. The Chumash: The Torah, Haftaros and Five Megillos, with a Commentary Anthologized from the Rabbinic Writings. Brooklyn, N.Y.: Mesorah Publications, 1998.

Scherman, Nosson, Meir Zlotowitz, and Sheah Branderr The Complete ArtScroll Siddur: Weekday, Sabbath, Festival: Nusach Ashkenaz. Brooklyn, N.Y.: Mesorah Publications, 1999.

Patrick Coyle is an artist and writer working predominantly with performance and sculpture. He has recently performed at Tate Modern, the Institute of Contemporary Arts and Whitechapel Gallery (London), Kunsthal Aarhus (Denmark), and Norwich Castle Museum and City Centre.

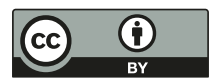

This chapter is distributed under the terms of the Creative Commons Attribution 4.0 International License (http://creativecommons.org/ licenses/by/4.0/), which permits use, duplication, adaptation, distribution and reproduction in any medium or format, as long as you give appropriate credit to the original author(s) and the source, a link is provided to the Creative Commons license and any changes made are indicated.

The images or other third party material in this chapter are included in the work's Creative Commons license, unless indicated otherwise in the credit line; if such material is not included in the work's Creative Commons license and the respective action is not permitted by statutory regulation, users will need to obtain permission from the license holder to duplicate, adapt or reproduce the material. 